ENTORNOS, No. 27. | Abril 2014

\title{
Análisis del proceso enseñanza-aprendizaje del Inglés en las instituciones educativas públicas del Huila
}

\section{Analysis of the English teaching-learning process at public educational institutions from Huila}

\section{Analyse des lehr- und lernprozesses von Englisch an den offentlichen bildungseinrichtungen von Huila}

\author{
Lilian Cecilia Zambrano Castillo ${ }^{1}$, Edgar Alirio Insuasty ${ }^{2}$
}

\begin{abstract}
Resumen
El propósito de este proyecto de investigación consistió en establecer de qué manera se ha venido orientando el proceso de enseñanza-aprendizaje del inglés en las instituciones educativas públicas del Departamento del Huila. Para alcanzar este propósito se acudió a los parámetros procedimentales de la investigación cualitativa descriptiva. La recolección de información se hizo a través de observación de clases, encuestas a profesores y estudiantes. El correspondiente análisis se realizó por medio de estadística descriptiva. Los principales hallazgos están relacionados con la prevalencia de prácticas pedagógicas precomunicativas o cuasi comunicativas, con la adopción de roles tanto de carácter estructural como comunicativos por parte de docentes y estudiantes, así como con la identificación de los factores que favorecen o dificultan la implementación de los estándares propuestos desde el Ministerio de Educación Nacional.
\end{abstract}

Palabras clave: prácticas pedagógicas, enfoque comunicativo, enfoque estructural, estándares básicos para lenguas extranjeras

\begin{abstract}
This study was an attempt to investigate how English was being taught at public schools in Huila Department. It was a descriptive study and data was collected through class observation, and surveys administered to teachers and students. The results demonstrated the prevalence of pre or quasicommunicative teaching practices, the adoption of both communicative and structural roles by teachers and students, and the identification of the factors that favor or hinder the implementation of the standards proposed by The Ministry of Education.
\end{abstract}

Keywords: teaching practices, communicative approach, structural approach, basic standards for foreign languages

\section{Zusammenfassung}

Dieses Forschungsprojekt möchte ergründen, auf welche Art und Weise der Lehr- und Lernprozess von Englisch an den öffentlichen Bildungseinrichtungen der Provinz Huila durchgeführt wird. Um dieses Ziel zu erreichen, behilft man sich mit den Verfahrensparametern der qualitativ-deskriptiven Forschung. Die Datenerhebung erfolgt durch eine Beobachtung der Klassen und durch Befragungen der Lehrenden und der Lernenden. Die Analyse der Information erfolgt mittels der deskriptiven Statistik. Die wichtigen Erkenntnisse müssen anhand der Häufigkeit der präkommunitativen oder quasi-kommunikativen pädagogischen Praxis, der Annahme der kommunikativen und strukturellen Rollen seitens der Dozenten und Studenten, sowie der Identifizierung der Faktoren, die die Einführung der vorgeschlagenen Standards durch das Nationale Bildungsministerium begünstigen oder erschweren, beurteilt werden.

1 - Magister en Didáctica del Inglés. Universidad de Caldas. Neiva. Colombia.

2 - Magister en Didáctica del Inglés. Universidad de Caldas. Neiva. Colombia. 


\section{Introducción}

La orientación del proceso de la enseñanza del inglés, en las instituciones educativas de básica secundaria, de la ciudad de Neiva, fue objeto de un estudio diagnóstico durante el año 2000. El principal hallazgo consistió en evidenciar el distanciamiento entre la expectativa legal, teórica e investigativa por un proceso más comunicativo en la enseñanza-aprendizaje de esta lengua extranjera y la ocurrencia de un proceso instruccional que no alcanzaba a perfilarse como auténticamente comunicativo, significativo o funcional (Zambrano \& Insuasty, 2001). En su momento, se identificaron como causas de este resultado la adopción de roles poco comunicativos por parte del profesor y de los estudiantes, el desarrollo las cuatro destrezas lingüísticas (escucha, habla, lectura y escritura) y los componentes de la lengua (sonidos, vocabulario y gramática) desde los parámetros del Método Audiolingual, la selección y utilización de materiales que no eran adecuados ni propicios para lecciones comunicativas, el desaprovechamiento del error como fuente de aprendizaje y mejoramiento, la inclinación hacia técnicas de corte audio lingual, estructural y la indecisión de usar el inglés como medio de interacción dentro y fuera del aula.

Ha transcurrido un poco más de una década desde la realización del mencionado estudio, y durante este lapso ha sucedido una serie de hechos alrededor de la profesión de la enseñanza-aprendizaje del inglés en la ciudad de Neiva. Entre éstos, se pueden mencionar: el ofrecimiento en la región de un programa de Especialización en Didáctica del Inglés por parte de la Universidad Surcolombiana y la Maestría en Didáctica del Inglés por parte de la Universidad de Caldas en convenio con la Universidad Surcolombiana, la vinculación de nuevos docentes de inglés al servicio de la educación municipal, departamental y, finalmente, la puesta en marcha de los denominados Programas de Bilinguismo por parte de las Secretarias de Educación Municipal y Departamental de Neiva. La ocurrencia de todos estos hechos justifica la expectativa de mejores resultados en el proceso de enseñanza-aprendizaje del inglés en nuestro contexto educativo.

No obstante, a pesar de las anteriores iniciativas, el nivel de inglés que demostraron los bachilleres que ingresaron a la Universidad Surcolombiana desde el 2010 hasta el 2012 no ha sido satisfactorio. Esto se evidenció a través de un examen de clasificación que todos los estudiantes de cada cohorte de pregrado deben presentar al iniciar de sus estudios. Los resultados obtenidos muestran que el $75 \%$ de los estudiantes de primer semestre no alcanzaron a ser clasificados en el nivel Al, como lo establece el Marco Común Europeo. El hecho de que la gran mayoría de estos estudiantes queden ubicados en el primer nivel evidencia que no vienen ni con conocimientos ni habilidades básicas en esta lengua extranjera, después de haber tomado y aprobado varios cursos en los ciclos de educación básica primaria y secundaria. Al ingresar a la universidad estos estudiantes tienen práctica- mente que empezar nuevamente su formación en lengua extranjera.

Estos resultados pueden obedecer a un sinnúmero de variables alrededor del contexto educativo, del docente y del aprendiz, entre otros. Con la presente investigación justamente se desea aportar a la búsqueda de explicaciones a la situación descrita, a través de la formulación y desarrollo de los siguientes objetivos investigativos:

- Caracterizar las prácticas pedagógicas que desarrollan los docentes en las clases de inglés, en las instituciones educativas del Departamento del Huila.

- Establecer los roles que desempeñan los docentes y aprendices en el proceso enseñanza-aprendizaje del inglés.

- Determinar las percepciones que tiene los docentes acerca de los factores que han favorecido y/o dificultado la implementación de los lineamientos teóricos y legales sobre la enseñanza de lenguas extranjeras, en las instituciones educativas del Departamento del Huila.

\section{Marco teórico}

La concepción de este estudio, así como la recolección y análisis de la información con respecto a las prácticas pedagógicas de los docentes de inglés, los roles de los docentes, los roles de los alumnos y la implementación de los estándares propuestos por el Ministerio de Educación Nacional, se hicieron con fundamento en los principios de la enseñanza comunicativa y de la enseñanza estructuralista del inglés, teniendo presentes igualmente los referentes legales que sirven de marco al proceso instruccional de los idiomas extranjeros en el sistema educativo colombiano.

\subsection{Enfoque comunicativo}

La enseñanza comunicativa de una lengua extranjera (ECLE) puede definirse como una de las opciones pedagógicas más difundidas y prevalentes que en las últimas décadas han adoptado muchos docentes de esta lengua extranjera para orientar sus clases y desarrollar la competencia comunicativa de sus alumnos.

El desarrollo de competencia comunicativa en una segunda lengua conlleva el cumplimiento de algunos principios básicos de aprendizaje. Entre ellos, se destacan los siguientes: 1) Según la teoría del aprendizaje significativo de Ausubel, citado por Brown (2007, p. 98) el aprendizaje sucede a través de un proceso significativo consistente en relacionar conceptos nuevos con el conocimiento que el aprendiz ya ha adquirido previamente; 2 ) el motivo principal para aprender una lengua es la existencia de una necesidad comunicativa; esto hace que los estudiantes sientan que están aprendiendo a hacer algo útil con la segunda lengua; 3) el éxito del aprendizaje 
comunicativo de una lengua depende de la calidad de oportunidades que se brinda al estudiante para hacer uso de la lengua; 4) la existencia de un ambiente sociohumanístico, impulsado por un profesor facilitador, le permite al aprendiz expresarse sin inhibiciones; 5) el input (o material lingüístico al que se expone al estudiante) debe ser comprensible, relevante a los intereses inmediatos, no demasiado complejo y que tampoco esté estrictamente graduado y que sea interesante de manera que contribuya a crear una atmósfera relajada en el aula de clase; 6) la interacción que conlleve negociación del significado facilita el proceso de adquisición de una segunda lengua.

El desarrollo de la competencia comunicativa implica la adquisición y uso de las denominadas habilidades lingüísticas, que desde el enfoque comunicativo se promueven de una forma integrada y con propósitos reales de comunicación. Para contribuir al desarrollo comunicativo de estas habilidades lingüísticas, el docente de inglés dispone de un continuum de opciones que van desde las denominadas actividades pre-comunicativas hasta las actividades propiamente comunicativas. Según Littlewood (1998), las primeras están basadas en la precisión y presentan estructuras, funciones y vocabulario; las segundas se centran en la fluidez e implican compartir e intercambiar información.

Las actividades pre-comunicativas se subdividen, a su vez, en actividades estructurales y actividades cuasicomunicativas. Las estructurales tienen que ver con la mecanización y práctica de las estructuras. Las cuasicomunicativas se basan en la comunicación y en la estructura de la lengua.

Entre las actividades pre o cuasi comunicativas podemos encontrar las siguientes: responder preguntas, completar conversaciones, ejercicios de falso y verdadero, lectura en voz alta, conversaciones guiadas, dictados, clasificación de la información, diálogos, canciones, escribir preguntas, scrambled sentences, scrambled paragraphs, transferencia de información.

A su turno, las actividades comunicativas se subdividen en actividades funcionales y actividades de interacción social. En las actividades de comunicación funcional, la interacción se torna menos controlada por convenciones artificiales y los significados que los aprendices necesitan expresar se vuelven menos predecibles. Hay igualmente una oportunidad creciente para que los aprendices expresen su propia individualidad en las discusiones. El profesor, estructura la citación de tal forma que los aprendices tengan que llenar un vacío de información o solucionar un problema.

Las actividades de comunicación funcional se subdividen básicamente en cuatro grupos: a) Compartir información con cooperación restringida, es decir cuando un aprendiz (o un grupo) posee información que otro aprendiz (o grupo) debe descubrir, b) Compartir información con cooperación irrestricta, en vez de únicamente formular y responder preguntas, los aprendices ahora pueden usar la lengua para describir, sugerir, pedir clarificación, cooperar unos con otros., c) Compartir y procesar información, aquí los aprendices no solamente deben compartir información, sino también discutirla y evaluarla con el propósito de solucionar un problema y d) Procesar información, el estímulo para la comunicación en este caso proviene de la necesidad de discutir y evaluar todos los hechos ya conocidos por los interlocutores, en parejas o en grupos, con el fin de resolver un problema o alcanzar una solución.

Las actividades de interacción social le adicionan a las actividades funcionales la dimensión de un contexto social más claramente definido. Sus rasgos más significativos son: (1) Los aprendices deben prestar mayor atención a los significados funcionales y sociales que la lengua transmite; (2) estas actividades se aproximan más cercanamente a la clase de comunicación que sucede por fuera del aula de clase; (3) los aprendices deben intentar comunicarse de una forma que no solamente sea efectivamente funcional, sino que se ajuste a las convenciones sociales que rigen la comunicación entre amigos o con mayor grado de formalidad, según se amerite; (4) en este tipo de actividades, generalmente no se necesita animar al estudiante para que se comunique; ellos automáticamente se acoplarán al rol social en la manera como hablen; (5) desde su lengua materna, los aprendices saben que toda el habla tiene implicaciones tanto funcionales como sociales y que deben procurar en últimas la aceptabilidad social como la efectividad funcional; (6) hay muchas maneras como el profesor puede preparar a sus alumnos para la comunicación en los variados contextos sociales en los que tendrá que actuar por fuera del aula; (7) dentro de las actividades de interacción social, se presenta también la discusión del aula como un contexto social. El aula es en sí mismo un contexto social real donde los aprendices y los profesores entran en unas relaciones sociales igualmente reales. Las técnicas más usuales dentro de las actividades de interacción social son la simulación y el juego de roles.

Como conclusión, el profesor debe considerar los siguientes factores para la escogencia del tipo de actividad de interacción social:

- Sobra advertir que el profesor debe correlacionar las exigencias lingüísticas de una actividad tan cercanamente como sea posible con las capacidades lingüísticas de sus aprendices.

- Se debe recordar que las estructuras y funciones no están sujetas a situaciones específicas.

- El profesor debe procurar máxima eficiencia y economía en el aprendizaje de sus estudiantes.

- Las situaciones deben ser capaces de estimular a los aprendices hacia un alto grado de compromiso comunicativo.

- Se espera también que los roles que desempeñen los alumnos tengan algún margen de ocurrencia en su vida real. 
El desarrollo de estas actividades implica el uso de unos materiales de instrucción que, dentro del enfoque comunicativo y según Richards \& Rodgers (2004), pueden ser de tres tipos: textos de clase, materiales basados en tareas específicas y textos auténticos. Las actividades que generalmente contienen estos materiales son diálogos auténticos, ejercicios comunicativos, juegos de roles, cuadernos de trabajo, entrevistas, gráficos, textos de lectura, avisos, etc.

El desarrollo de actividades comunicativas en el aula implica igualmente que el docente y los aprendices asumen unos roles determinados. En lo que corresponde al docente, Richards \& Rodgers (2004) señalan que uno de esos roles es el de facilitador, el que promueve la comunicación entre todos los participantes. "En este rol, una de sus principales responsabilidades es propiciar situaciones que promuevan la interacción". Durante las actividades el docente actúa como consejero contestando las preguntas de los estudiantes y monitoreando su desempeño" (Larsen \& Freemman, 2000, p.128). Vanegas \& Zambrano (1997) consideran que para convertirse en un verdadero facilitador del desarrollo de la competencia comunicativa, el profesor deberá realizar varias acciones, entre ellas están: exponer a los estudiantes a un Input significativo, escoger los materiales apropiados que promuevan interacción, generar un ambiente de aprendizaje interesante y agradable, promover el aprendizaje autónomo, entre otros. Otro papel es el de comunicador, oparticipante como lo denomina Harmer (2007). En este papel, se espera que el docente a veces participe activamente en tareas que promuevan la interacción entre los estudiantes, como debates, teniendo cuidado de no controlar la actividad, sino avivar o estimular la discusión. El rol de consejero implica, según Larsen \& Freeman (2010), que el profesor proporciona retroalimentación a partir de las fortalezas y debilidades de los estudiantes en el desarrollo de la competencia comunicativa.

En cuanto al rol del aprendiz, Bastidas (1993) establece que el alumno debe jugar un papel activo y que debe ser responsable de su propio aprendizaje. "El estudiante debe ir independizándose poco a poco en su búsqueda de los nuevos conocimientos puesto que el ECO enfatiza en el aprender haciendo" (P.173). Larsen \& Freeman (2000) añaden que el aprendiz debe convertirse en un negociador de significados para entender a sus interlocutores y también hacerse entender, agrega que el estudiante debe ser ante todo comunicador. Richards \& Rodgers (2004) por su parte señalan que el aprendiz debe ser un negociador entre el mismo, el proceso de aprendizaje y el objeto de estudio.

Finalmente, y con respecto al tratamiento de los errores en el enfoque comunicativo, Larsen \& Freeman (2000) señalan que los errores estructurales son considerados como un producto natural dentro del desarrollo de las habilidades comunicativas, por lo tanto un estudiante que tenga un conocimiento limitado de la competencia lingüística podría comunicarse efectivamente. Dentro de los enfoques comunicativos se sugiere ser tolerantes con los errores de los aprendices.

\subsection{Enfoque estructuralista para la enseñanza de la lengua extranjera}

En términos generales, el método audiolingual se fundamenta en una visión estructuralista del lenguaje, en virtud de la cual cada lengua es concebida como un sistema de elementos estructuralmente relacionados para la codificación del significado. Estos elementos son los fonemas, los morfemas, las palabras, las estructuras y los tipos de oraciones (Richards \& Rodgers, 2004).

Por otro lado, Richards \& Rodgers (2004) sostienen que el método audiolingual se centra en un enfoque conductista; es decir que, como lo señala Bastidas (1993) "el aprendizaje se asume como un cambio de conducta que se logra a través de la práctica positivamente reforzada" (p. 64). Richards \& Rodgers (2004) "señalan que el aprendizaje de una lengua extranjera es básicamente un proceso de formación de hábitos mecánicos. Los buenos hábitos se consiguen a través de respuestas correctas, sin cometer errores" ( $p$. 57).

Según Nunan (2006) el desarrollo de patrones y ejercicios de sustitución representó un matrimonio entre el análisis lingüístico estructural y la formación de hábitos conductistas. A partir de la convergencia de estos dos enfoques, se identifican los siguientes principios que caracterizan al Método Audiolingual:

- La lengua es habla y no escritura

- La lengua es un conjunto de hábitos

- Enseñe la lengua, no acerca de la lengua

- La lengua es lo que los hablantes nativos dicen, y no lo que alguien más piense que ellos deberían decir

- Las lenguas son diferentes

Con respecto a las principales técnicas utilizadas por los profesores en el Método Audiolingual, Larsen \& Freeman (2010) indica que "el nuevo vocabulario y los nuevos patrones estructurales se presentan en forma de diálogo. Los diálogos se aprenden a través de imitación y repetición" (p. 45). Ejercicios de mecanización tales como las repeticiones, las substituciones, las transformaciones, preguntas y respuestas se desarrollan con base en los patrones que están presentes en los diálogos. Las respuestas exitosas de los alumnos son positivamente reforzadas.

Littlewood (1998) clasifica las actividades estructurales del audiolingualismo como actividades precomunicativas las cuales tienen el propósito de suministrarles a los estudiantes un dominio fluido del sistema linguístico, sin realmente exigirles que lo usen para propósitos comunicativos (p. 85). Larsen \& Freeman (2010) ofrece una descripción de técnicas de 
instrucción de carácter audiolingual tales como memorización de diálogos, técnica del backward build-up, ejercicios de repetición, ejercicios en cadena, ejercicios de sustitución simple, ejercicios de sustitución múltiple, ejercicios de transformación, uso de pares mínimos, complementación de diálogos y juegos gramaticales.

Según Richards \& Rodgers (2004), los materiales instruccionales en el Método Audiolingual le ayudan al docente a desarrollar el dominio de la lengua por parte de los estudiantes. Los reproductores de audio y el equipo audiovisual juegan un papel central en este método (p. 63). Brown (2007) dice que hay mucho uso de cintas de audio, laboratorios de audio y ayudas visuales.

En lo que corresponde a los roles del docente audiolingual, Larsen \& Freeman (2010) lo describen como un director de orquesta que dirige y controla el comportamiento lingüístico de los estudiantes. De igual modo, se percibe como el responsable de suministrarle a sus estudiantes un buen modelo para imitar (Pág. 45). En este mismo sentido, Nunan (2006) señala que las actividades audiolinguales son dominadas por el docente que sirve de modelo y controla la orientación y el ritmo de la clase (pág. 184).

Harmer (2007) igualmente alude al papel del docente como "controlador" quien lidera las actividades de clase desde el frente, organizando los ejercicios mecánicos, dando instrucciones, llevando registros y transmitiéndoles a sus estudiantes conocimientos (Pág. 108) sobre la lengua objeto de estudio.

En cuanto a los aprendices, ellos se desempañan básicamente como imitadores de los modelos del docente; siguen las instrucciones de éste de la manera más precisa y rápida posible (Larsen \& Freeman, 2010). Richards \& Rodgers (2004) afirman que "los aprendices, desde una teoría conductista de aprendizaje, juegan un papel reactivo al responder a los estímulos del profesor y que tienen bajo control sobre el contenido, el ritmo o el estilo de aprendizaje" (Pág. 62); es decir, que son unos receptores pasivos en el sentido de no tomar la iniciativa de interactuar con su profesor o sus compañeros para propósitos propiamente comunicativos.

Finalmente, en cuanto a la postura del Método Audiolingual frente al manejo de los errores, hay un gran esfuerzo por lograr que los estudiantes produzcan enunciados exentos de errores (Brown, 2007). Larsen \& Freeman (2010) arguyen la importancia de prevenir que los estudiantes cometan errores, puesto que estos conducen a la formación de malos hábitos (p. 43). Por su parte, Ur (2009, p. 244) manifiesta que en el audiolingualismo, en principio, se evitan los errores del aprendiz puesto que limitan su progreso. Argumenta que la corrección no resulta útil para el aprendizaje, que las personas aprenden mediante aciertos que sean reforzados.

\subsection{Políticas colombianas para la formación en lengua extranjera}

Hoy por hoy, Colombia dispone de unas políticas educativas que realzan, por un lado, la trascendencia social y cultural que reviste la formación de los educandos colombianos en una segunda lengua y, por otro, trazan las principales orientaciones curriculares y metodológicas que los docentes de inglés pueden explorar para facilitar el proceso de adquisición comunicativa de esta lengua extranjera por parte de sus alumnos, en los diferentes niveles del sistema educativo.

En efecto, el Ministerio de Educación Nacional en las dos últimas décadas ha concebido y divulgado los lineamientos y estándares curriculares que sirven de referencia para los procesos de enseñanza-aprendizaje de las lenguas extranjeras. A diferencia de lo que sucedía en otros tiempos con la expedición de un currículo único nacional, el MEN sostiene haber asumido con las últimas disposiciones un rol de orientador y facilitador para que las diversas comunidades educativas construyan sus propias propuestas educativas, de acuerdo con las características, intereses y expectativas socio-culturales de su entorno.

Sin embargo, se han presentados numerosas críticas al hecho de que la principal fuente de inspiración para los estándares haya sido el Marco Común Europeo que, según varios académicos de reconocida trayectoria como Vargas, Tejada \& Colmenares, Sánchez \& Obando, Guerrero, Guerrero \& Quintero, no es representativo de la identidad cultural de país, toda vez que este marco está pensado para un sistema educativo con características disímiles al nuestro.

\section{Metodología}

El presente estudio fue orientado desde la perspectiva de una investigación cualitativa descriptiva cuyo objetivo central fue la descripción de los fenómenos, en donde la recolección y análisis de información se realizó mediante encuestas a docentes y estudiantes, como también a través de observaciones directas e indirectas de las clases. Según Hernández, Fernández \& Baptista (2006), las investigaciones cualitativas se fundamentan más en un proceso inductivo que implica "explorar, describir y luego generar perspectivas teóricas. Señalan también que la recolección de datos consiste en obtener las perspectivas y puntos de vista de los participantes como sus experiencias, opiniones y otros aspectos subjetivos. Patton (citado por Hernández, et al. 2006) complementa que "los datos cualitativos son descripciones detalladas de situaciones, eventos, personas, interacciones, conductas observadas y sus manifestaciones" (p. 8).

En términos generales, según Hernández et al. (2006), el enfoque cualitativo sugiere el siguiente procedimiento: 
- Planteamiento del problema

- Revisión de literatura

- Recolección de datos

- Análisis de los datos

- Reporte de los resultados

Los sujetos que participaron en este estudio fueron 78 docentes de inglés y 1261 estudiantes de la educación básica secundaria de 35 de las instituciones educativas públicas en las ciudades de Neiva, Garzón, Pitalito y La Plata.

Los instrumentos que fueron usados en este estudio son los siguientes:

Encuesta a docentes: esta encuesta tenía como propósito recoger información sobre el conocimiento que tienen los docentes de inglés de los principios y lineamientos básicos, las metodologías comunicativas para la enseñanza y aprendizaje de lenguas extranjeras. Por otra parte, determinar la percepción que tienen los profesores sobre los factores que favorecen y/o dificultan la puesta en marcha de los estándares establecidos por el MEN.

Encuesta a estudiantes: la segunda encuesta, tenía como propósito determinar las percepciones que tienen los estudiantes sobre la orientación metodológica, los materiales, las actividades, las actitudes que los docentes realizan en sus clases de inglés.

Observación de clases: el objetivo de la observación de clases fue determinar las metodologías implementadas por los docentes y también caracterizar las prácticas pedagógicas usadas.

Con respecto al procedimiento, se siguieron los siguientes pasos:

- Recolección de información a través de la aplicación de encuesta a estudiantes y docentes.

- Observación de clases

- Sistematización de información (codificación y categorización de datos)

- Triangulación de información

- Análisis y discusión de información

- Elaboración del informe final de investigación

- Redacción de un artículo para revista indexada

- Ofrecimiento de conferencia sobre la experiencia investigativa

\section{Análisis de resultados}

\subsection{Rasgos que caracterizan las prácticas pedagógicas utilizadas por los docentes de inglés}

Para responder este primer interrogante, se valoró el comportamiento de cinco categorías (tratamiento de las habilidades lingüísticas, tratamiento de los componentes de la lengua, manejo de errores, materiales de instrucción y técnicas de instrucción), desde las perspectivas de los docentes, de los estudiantes y de los observadores externos.

\subsubsection{Habilidades lingüísticas}

El análisis de las respuestas de los docentes y estudiantes en las encuestas deja ver algunas coincidencias y divergencias que existen entre ellos en la forma de valorar la mayor frecuencia y orientación de las actividades que promueven el desarrollo de las cuatro habilidades lingüísticas.

Figura 1. Tratamiento de la habilidad de escucha desde perspectiva de docentes

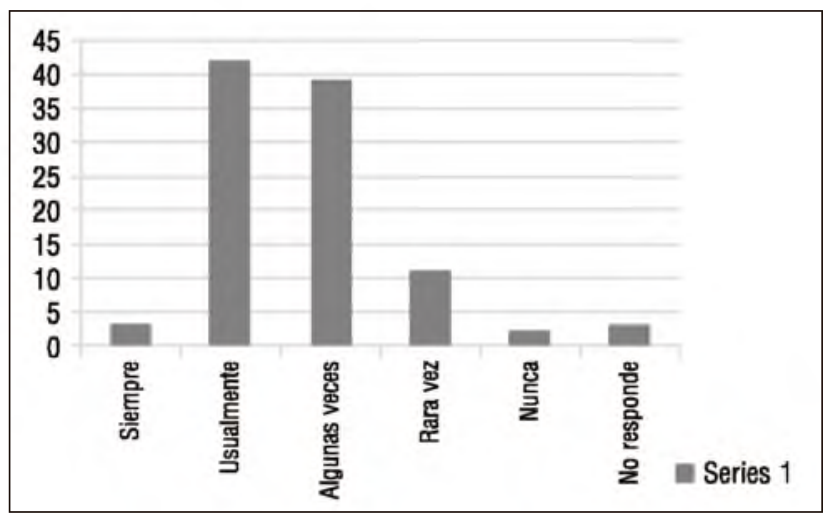

Fuente : Encuesta a docentes

La Figura 1 revela que el 3\% de los docentes admiten que ellos siempre hacen escuchar grabaciones a sus estudiantes con el fin de hacer ejercicios de comprensión tales como contestar preguntas o completar cuadros. El $42 \%$ de ellos sostienen que lo hacen usualmente. El 50\%, en cambio, le dio a esta práctica otros niveles de frecuencia menores. Sólo el $2 \%$ sostuvo que nunca se dieron este tipo de ejercicios. El 3\% de los docentes no contestó la pregunta.

Figura 2. Tratamiento de la habilidad de escucha desde perspectiva de estudiantes

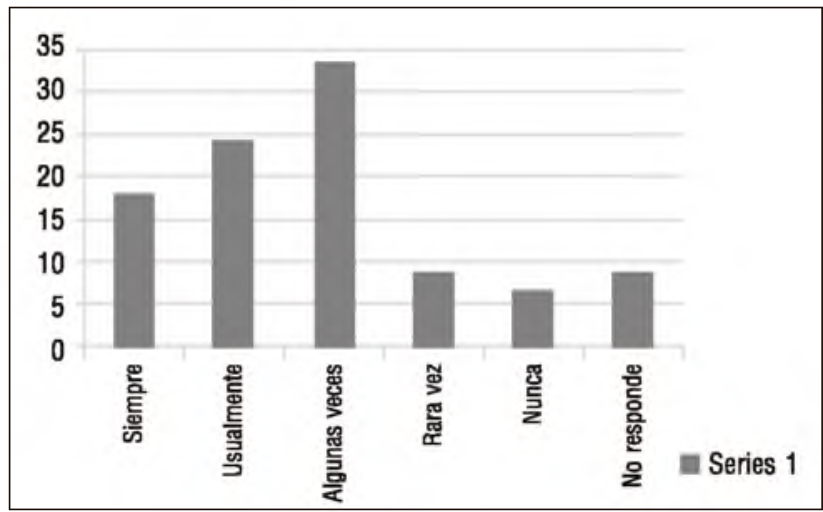

Fuente : Encuesta a estudiantes

Según los datos de la figura 2, el 18\% de los estudiantes reconocen que ellos siempre desarrollaban ejercicios de comprensión de escucha con ayuda de grabaciones. El 24\% afirma que esto sucedia usualmente. Otro $42 \%$ lo hace con rangos menores de frecuencia. Solo el $7 \%$ afirma que nunca se presentaba este tipo de ejercicios y un $9 \%$ no registra respuesta. 
Figura 3. Tratamiento de la habilidad de escucha desde la observación de clase

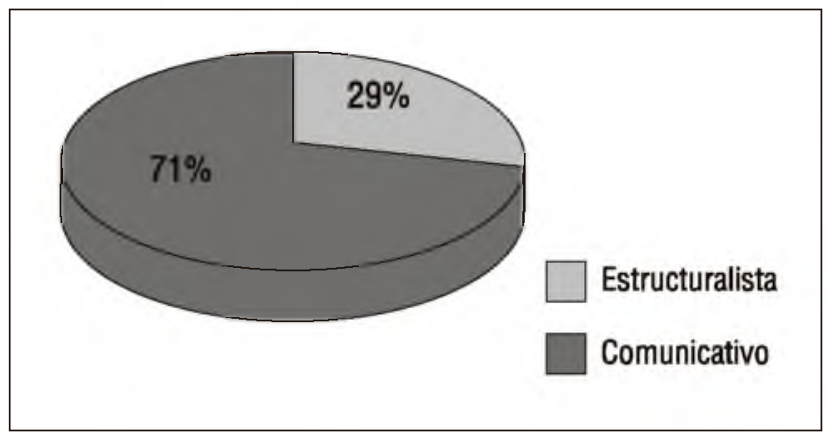

Fuente: Transcripciones de observaciones de clase

A partir de la figura 3, se infiere que para el $71 \%$ de los observadores, la habilidad de escucha se trabajó de manera comunicativa. El alcance de este tratamiento se puede evidenciar en el siguiente registro de uno de los observadores:

"Al desarrollar la actividad de hablar sobre un tema de interés y reportar noticias, los estudiantes escuchan los reportes, intereses de sus compañeros. Igualmente, escuchan las órdenes de la profesora y un dictado".

En términos generales, se percibe que la habilidad de escucha se está trabajando de una manera cuasi comunicativa ya que con base en la escucha de grabaciones los estudiantes respondían preguntas, sin alcanzar a participar en situaciones de comunicación funcional tal como lo describe Littlewood (1998).

Con respecto al tratamiento de la habilidad del habla, se obtuvieron los siguientes resultado:

Figura 4. Tratamiento de la habilidad de habla desde perspectiva de docentes

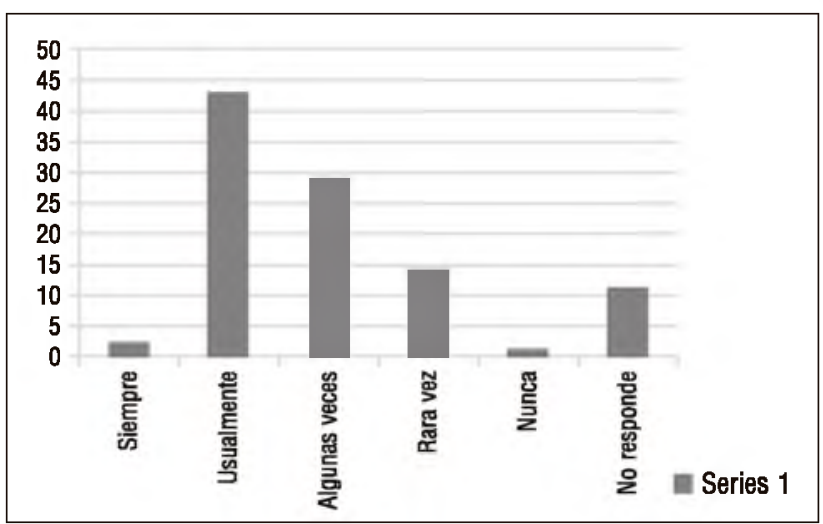

Fuente: Encuesta a docentes

En la Figura 4, se observa que el $2 \%$ de los docentes afirman que los alumnos siempre hablan en inglés cuando contestan las preguntas que el maestro les formula. El $43 \%$ sostiene que los alumnos usualmente tenían este comportamiento. Otro $43 \%$ señalan la ocurrencia de esta práctica con menores rangos de frecuencia. Tan solo el 1\% indicó que nunca se presentaba y el $11 \%$ no dio respuesta alguna.

Figura 5. Tratamiento de la habilidad de habla desde perspectiva de estudiantes

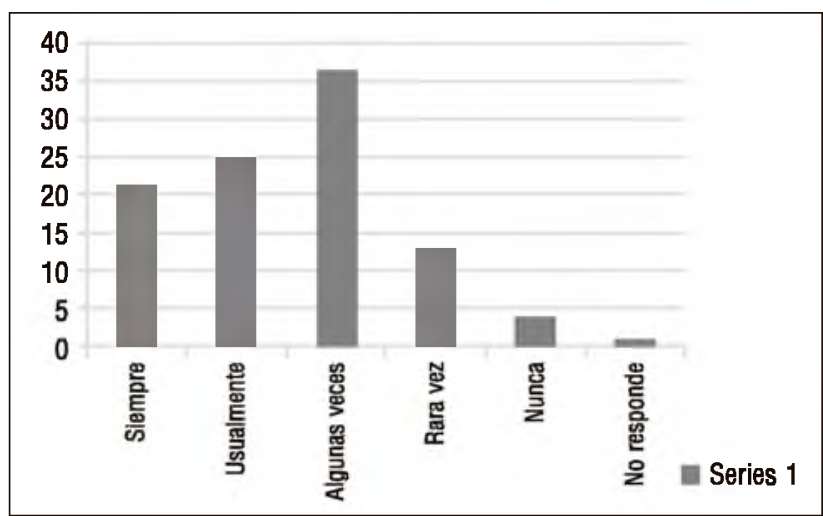

Fuente: Encuesta a estudiantes

La figura 5 muestra que el $21 \%$ de los estudiantes admiten que siempre hablaban en inglés cuando contestan las preguntas que el maestro les formulaba. El 25\% manifiesta que usualmente participaban en clase de esta manera. El 49\% lo reconocen con rangos menores de frecuencia. El 4\% afirman que nunca y el 1\% no respondió la pregunta.

Figura 6. Tratamiento de la habilidad de habla desde la observación de clases

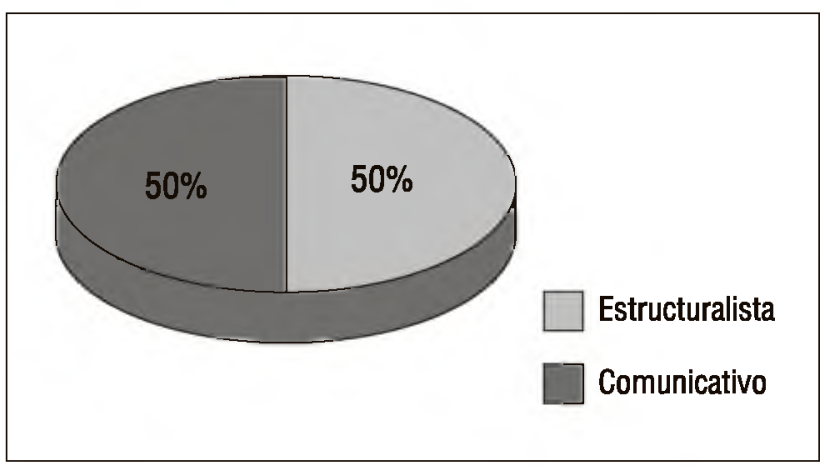

Fuente: Transcripciones de observaciones de clase

La figura 6 indica que el desarrollo de la habilidad del habla fue de carácter comunicativo para el $50 \%$ de los observadores y de carácter estructuralista para el otro 50\%.El siguiente relato de uno de los observadores refleja los esfuerzos que hace un profesor por orientar su clase con un enfoque comunicativo:

"The class starts. The teacher greets students. The teacher explains that they are going to have 3 minutes to talk about a topic

One of them starts talking about love. At the end of her presentation, the student asks her classmates two questions related to the presentation to check if they had paid attention.

Ss answers the questions and clap. The girl sits down" 
Este tipo de actividades no se promueven con mucha frecuencia. Como se puede apreciar, la gran mayoría de los docentes y estudiantes consultados están de acuerdo con admitir la implementación de un enfoque estructuralista o cuasi comunicativo para el desarrollo de la habilidad del habla, lo que revela la falta de la iniciativa interactiva por parte de los estudiantes. Ellos generalmente hablan en inglés para contestar las preguntas del docente.

En cuanto al desarrollo de la habilidad de lectura, se procuró averiguar si se sigue acudiendo a la traducción como estrategia de comprensión. Estos fueron los resulatdos al respecto:

Figura 7. Tratamiento de la habilidad de lectura desde la perspectiva de los docentes

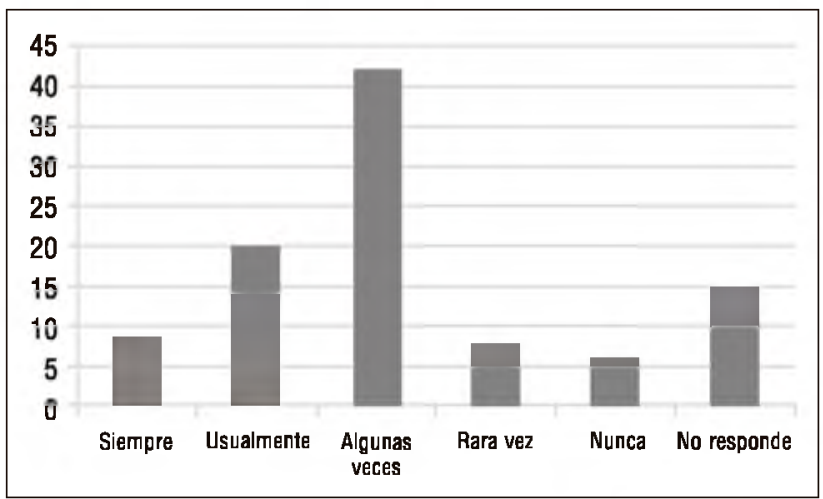

Fuente: Encuesta a docentes

Según la Figura 7, el 9\% de los docentes admiten que promueven la traducción como manera de facilitar la comprensión de textos en inglés por parte de los estudiantes. El 20\% de ellos afirman que usualmente proceden de esta manera. El 50\% lo hace con rangos menores de frecuencia. Solo el $6 \%$ niega hacerlo y $15 \%$ no ofrece una respuesta explícita al respecto.

Figura 8. Tratamiento de la habilidad de la lectura desde perspectiva de estudiantes

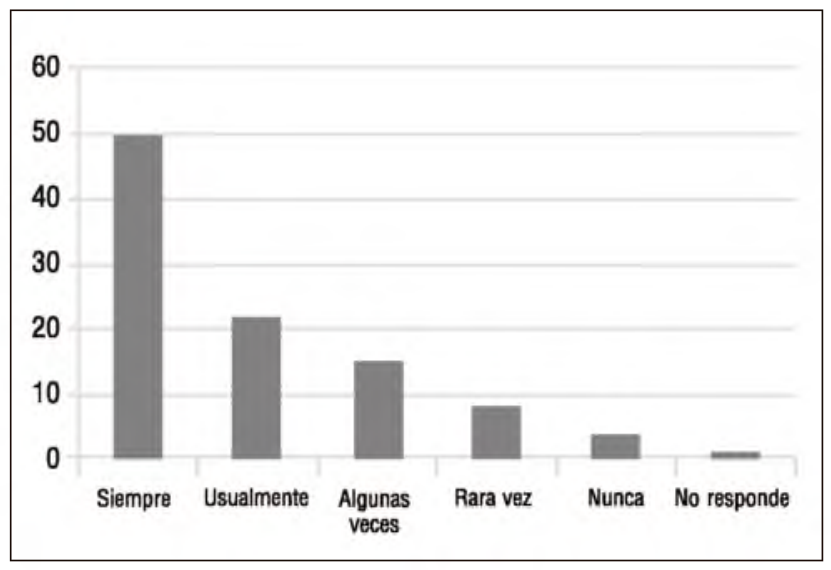

Fuente: Encuesta a estudiantes
La Figura 8 revela que el $50 \%$ de los estudiantes reconocen el uso de la traducción como estrategia para comprender un texto escrito. Un 22\% manifiesta que esto sucedía de manera habitual. Con unos rangos inferiores de frecuencia, el $23 \%$ de ellos también lo corroboran. Tan solo el $5 \%$ niega la utilización de esta estrategia estructuralista.

Figura 9. Tratamiento de la habilidad de lectura desde la observación de clases

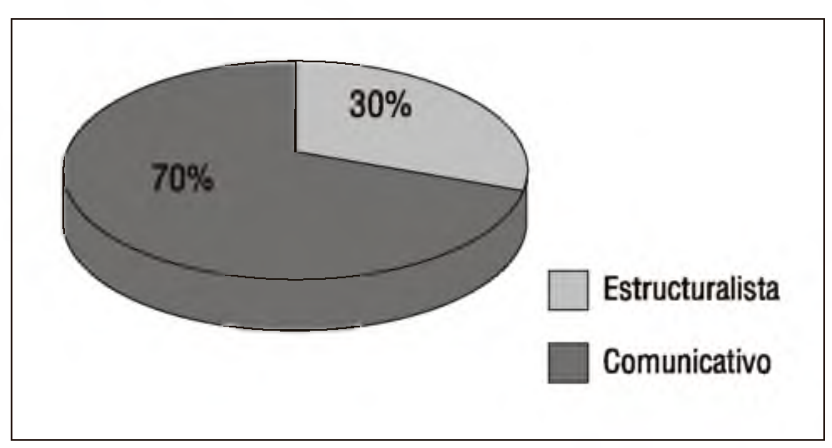

Fuente : Transcripciones de observaciones de clase

La figura 9, revela que la implementación de la habilidad de lectura fue percibida como comunicativa por parte del $70 \%$ de los observadores y como estructuralista por el 30\%. Uno de los observadores nos aporta el siguiente registro que evidencia que la comprensión de lectura se viene tratando de una manera comunicativa al centrar la atención instruccional en el desarrollo de sub habilidades tales como skimming, scanning e inferencia, más allá de depender de la traducción para comprender los textos de lectura :

"Tienen un plan lector. Al momento los estudiantes están leyendo "Blackbeard 's Treasure". Los estudiantes leen las respuestas a ejercicios y los capítulos del libro (plan lector) desarrollando sus micro habilidades de lectura".

La divergencia entre la opinión de los observadores y lo que manifiestan los docentes y estudiantes con respecto al tratamiento de la habilidad de lectura puede tener como posible explicación la observación de unas clases cuidadosamente planeadas por parte de los docentes, toda vez que las visitas fueron concertadas con ellos.

En lo que corresponde al tratamiento instruccional dado a la habilidad de escritura, se recogieron los siguientes resultados: 
Figura 10. Tratamiento de la habilidad de escritura desde percepción de los docentes

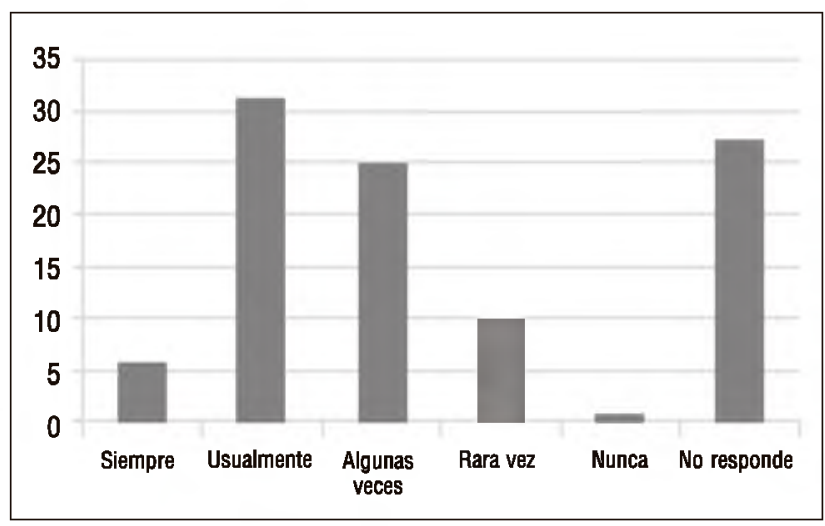

Fuente : Encuesta a docentes

El 6\% de los docentes afirman que sus estudiantes escriben en inglés párrafos o textos cortos. El 31\% sostienen que ellos usualmente promovían este tipo de práctica escritural. El 35\%, con menores rangos de frecuencia, también confirman la realización de este tipo de ejercicios. Tan solo el 1\% niega su ocurrencia. Hubo un $27 \%$ que no contestó la pregunta.

Figura 11. Tratamiento de la habilidad de escritura desde percepción de estudiantes

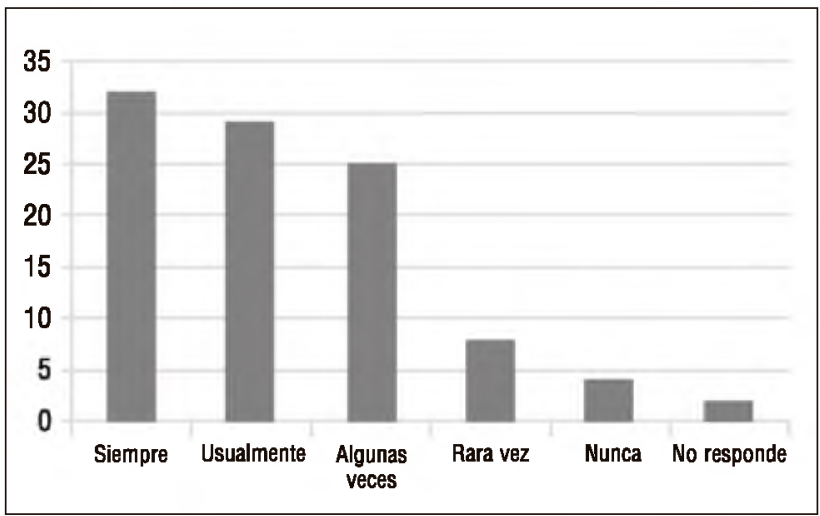

Fuente: Encuesta a estudiantes

A partir de la figura 11, la escritura de párrafos o composiciones sobre diferentes temas es reconocida como una actividad comunicativa habitual por parte del $61 \%$ de los estudiantes. Con menores índices de frecuencia esta habilidad fue igualmente calificada como comunicativa por parte del $33 \%$ de los estudiantes. Unicamente el $4 \%$ dio una respuesta negativa. $\mathrm{El} 2 \%$ no respondieron la pregunta.
Figura 12. Tratamiento de habilidad de escritura desde observación de clases

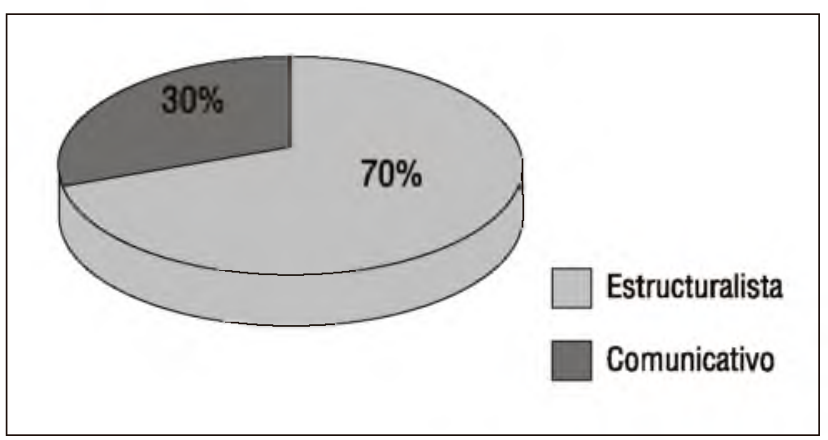

Fuente: Transcripciones de observaciones de clase

Con base en la figura 12, se determina que la destreza de la escritura fue apreciada como comunicativa por el $70 \%$ de los observadores y como estructuralista por el $30 \%$, en las pocas ocasiones cuando se presentaba este tipo de actividades. Sin embargo, una revisión más detallada del tipo de ejercicios de escritura que se promueven en los colegios focalizados permite establecer que su alcance es pre-comunicativo, tal como lo deja ver un observador :

"Se promueven ejercicios para reforzar las estructuras gramaticales"

Finalmente, las notables divergencias que se aprecian entre la forma de valorar la orientación metodológica de los docentes de inglés en cada una de las habilidades lingüísticas por parte de los mismos docentes, sus alumnos y los observadores externos pueden tener como posible explicación el hecho de que los docentes y alumnos fundamentan sus opiniones en una mayor familiaridad con su realidad educativa; los observadores, en cambio, solo tienen una apreciación ocasional de lo que allí sucede. Además no todos los profesores que contestaron la encuesta permitieron que sus clases fueran observadas.

Adicionalmente, desde la percepción de los observadores que visitaron las clases de inglés, se lograron establecer otros rasgos que caracterizan el tratamiento instruccional que se da a las cuatro habilidades lingüísticas. Uno de estos tiene que ver con la ocurrencia de distintas formas de integrar las habilidades. El 69\% de los observadores, por ejemplo, verificaron la integración de escucha-habla, lectura-escritura y lectura-habla. Por otro lado, el $40 \%$ encontraron integración de escucha-escritura y tan solo un $27 \%$ la integración habla-escritura.

El 54\% de los observadores reconocen una intencionalidad comunicativa en esas integraciones, es decir, que se hacían con el propósito de propiciar el uso del idioma en situaciones que reflejan la realidad. El otro $46 \%$, en cambio, se mostró partidario de que las habilidades se integraban para reforzar un determinado tema gramatical. 


\subsubsection{Componentes de la lengua}

Con respecto al tratamiento metodológico para la enseñanza de la gramática, se allegó la siguiente información:

Figura 13. Percepción de docentes sobre enseñanza de gramática

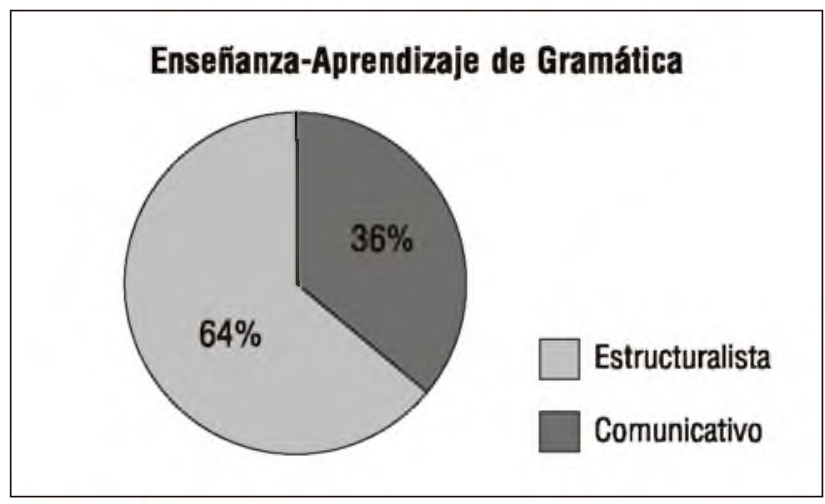

Fuente:Encuesta a docentes

Los resultados de la figura 13, nos permite evidenciar que la enseñanza de la gramática, según la percepción de los docentes, se hace en un 64\% a través de actividades que favorecen la práctica de la estructura de la lengua dentro de un enfoque estructuralista. Las actividades que se privilegiaron de mayor a menor frecuencia de uso son: Explicaciones de reglas gramaticales, transformación de oraciones, y repetición de patrones.

Figura 14. Percepción de los estudiantes sobre enseñanza de gramática

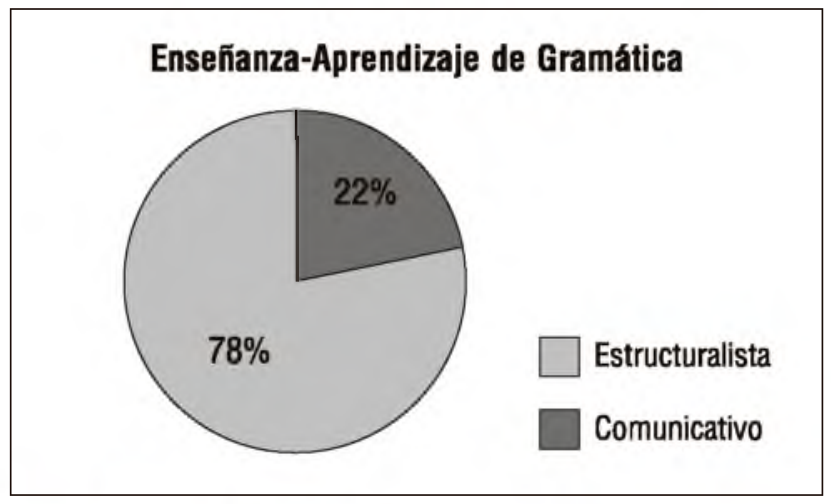

Fuente : Encuesta a estudiantes

Esta tendencia es corroborada por los estudiantes. La figura 14 muestra un $78 \%$ orientado a actividades de corte estructural, que incluyen el mismo tipo de ejercicios mencionados anteriormente, frente al $22 \%$ que mencionan actividades comunicativas. Sin embargo, en las clases observadas se notó que un 50\% de las actividades fueron de carácter estructural, y el $50 \%$ de tipo comunicativo.
Figura 15. Enseñanza de vocabulario desde observación de clase

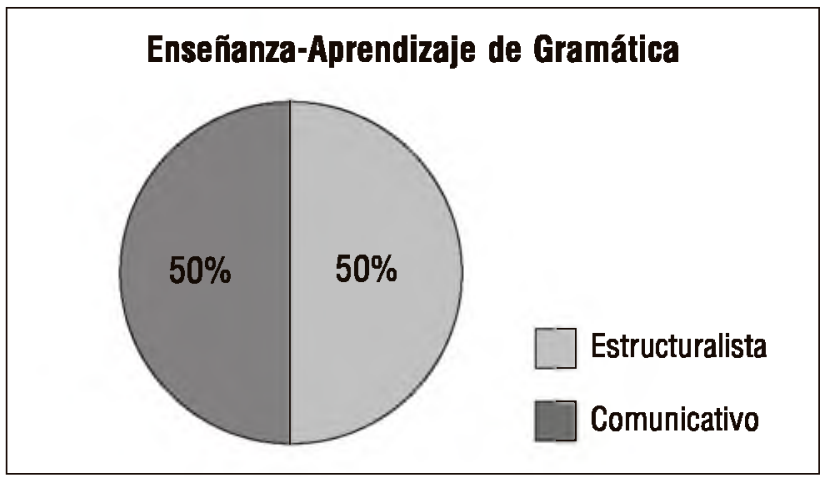

Fuente: Transcripciones de observaciones de clase

Un ejemplo del proceder estructuralista de los docentes es el siguiente:

"Después de haberle preguntado a todos los estudiantes los verbos, les pide que dividan el salón en dos grupos $(A, B)$ para realizar una actividad la cual consistía en que la profesora tenía una bolsa que contenía los 20 verbos en infinitivo que iba a evaluar, el tablero estaba dividido en 4 partes (infinitive, past simple, past participle and spanish) lo que tenían que hacer los estudiantes era escoger un estudiante de cada grupo, pasar al frente, sacar un papelito de la bolsa, y escribir el verbo en las 4 formas, si lo hacía correctamente ganaban un punto y si no la profesora junto con todos los estudiantes corregían la forma correcta del verbo y se le daba la oportunidad a otro estudiante del otro grupo, el ejercicio se hizo hasta que todos los estudiantes participaron".

Es importante también mencionar, que tanto docentes como estudiantes nos dan a conocer que hay otro tipo de actividades que se utilizan también para reforzar el uso de patrones gramaticales, aunque se promueven con menor frecuencia. Entre estas están: historietas, juego de roles, descripción de láminas, programa English Discoveries, lecturas, canciones y juegos.

Con referencia al desarrollo del vocabulario, se logró determinar lo siguiente:

Figura 16. Percepción de docentes sobre enseñanza de vocabulario

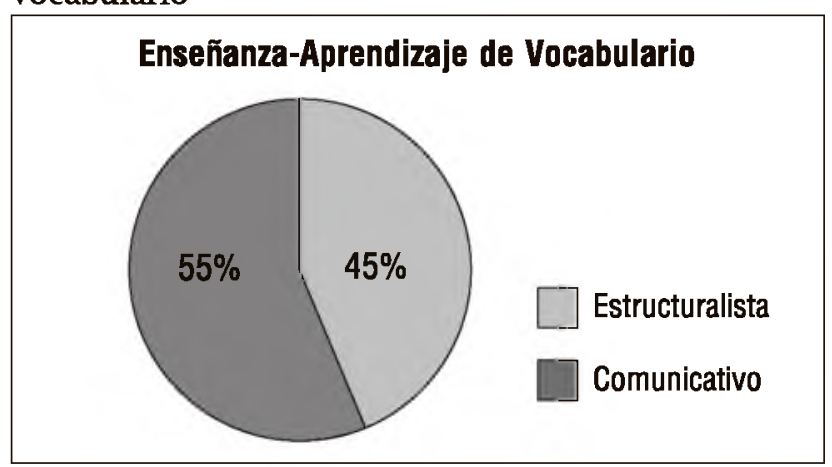

Fuente: Encuesta a docentes 
La figura 16 muestra la percepción de los docentes sobre la forma como se enseña el vocabulario en las clases de Inglés; este se orienta en mayor porcentaje desde una perspectiva estructuralista. Las técnicas que más se utilizan son la traducción al español, memorización de las palabras nuevas y repetición.

Figura 17. Percepción estudiantes sobre enseñanza de vocabulario

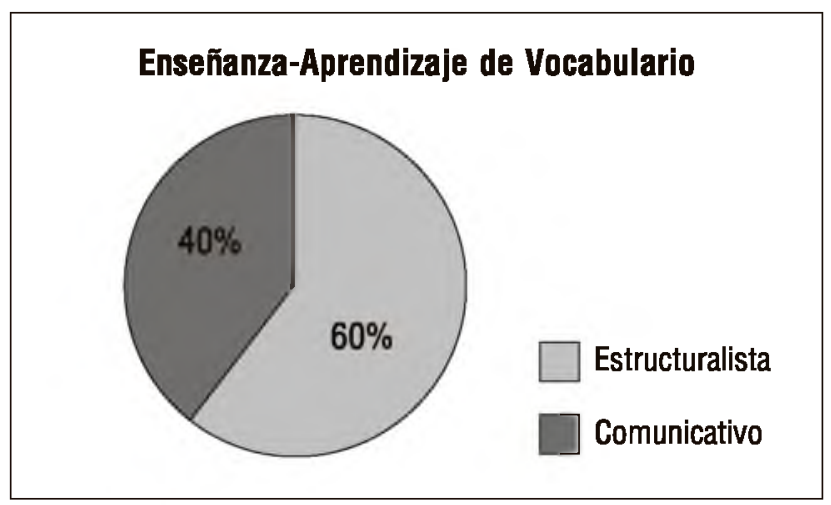

Fuente: Encuesta a estudiantes

En cuanto a la percepción de los estudiantes, la tendencia estructuralista sobre la enseñanza del vocabulario es aún mayor según el porcentaje de la figura 17. Las técnicas a las que hacen referencia los estudiantes son igualmente traducción, repetición y memorización de listas.

Entre las estrategias de orden más comunicativo que tanto docentes como estudiantes mencionan están: definición de palabras en inglés, sinónimos y antónimos, juegos, aplicación en contexto, crucigrama, parafraseo, textos de lectura, videos, exposiciones, también se mencionan materiales como láminas y objetos reales.

Figura 18. Enseñanza de vocabulario desde la observación de clases

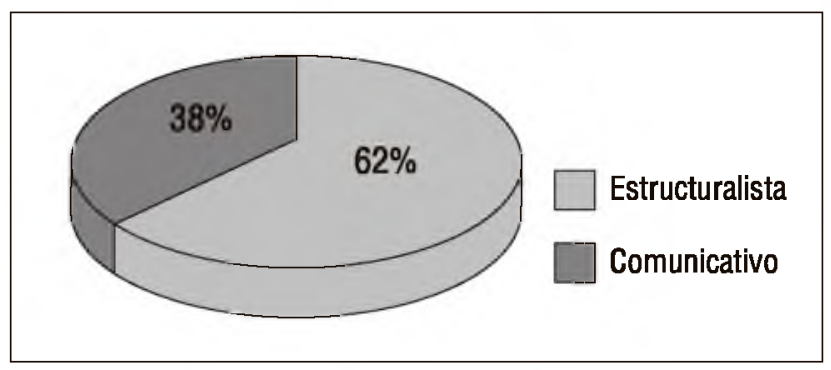

Fuente: Transcripciones de observaciones de clase

Finalmente, en la figura 18 que representa los resultados obtenidos a través de las observaciones de clase, se puede evidenciar que definitivamente, este componente se enseña a través de técnicas que favorecen más los lineamientos de un enfoque estructuralista que comunicativo. El $62 \%$ de las actividades que se promovieron para enseñar vocabulario muestran que a los estudiantes no se les proporcionan tareas que promuevan más el uso del idioma, y en donde los pueden poner en práctica todas las expresiones y palabras que han estudiado. Los docentes se quedan cortos en promover tareas que se clasifican según Littlewood (1998) de corte mas funcional y social, en donde los estudiantes puedan demostrar un manejo mas comunicativo de la lengua exranjera. Sin embargo, como se refleja en la siguiente narrrativa de uno de los observadores, los docentes hacen su mejor esfuerzo por promover un aprendizaje funcional del idioma extranjero:

"Game time. The teacher asks for a volunteer and explains the rules of the game. The participant has to choose a word (which is written on a piece of paper she has previously stock on the board), then draw it on the board and the rest of the class guess. The person who guesses tells a sentence using the word".

\subsubsection{Manejo de errores}

Otro de los aspectos que fueron objeto de indagación es la manera como los docentes abordan la corrección de los errores que cometen los estudiantes:

Figura 19. Corrección de errores desde la perspectiva de los docentes

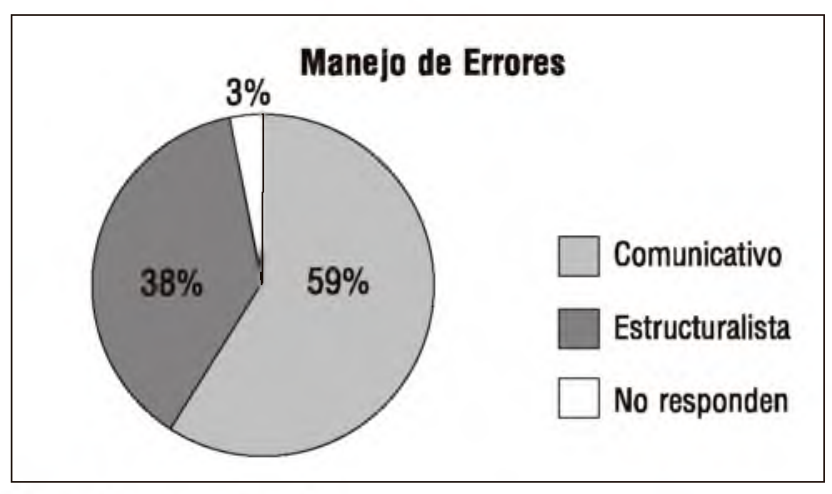

Fuente:Encuesta a docentes

Figura 20. Corrección de errores desde la perspectiva de los estudiantes

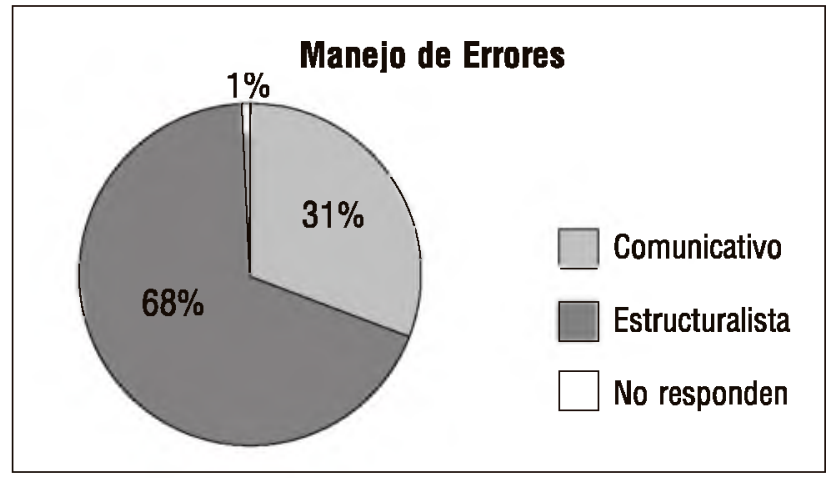

Fuente: Encuesta a estudiantes 
Figura 21. Corrección de errores desde la observación de clases

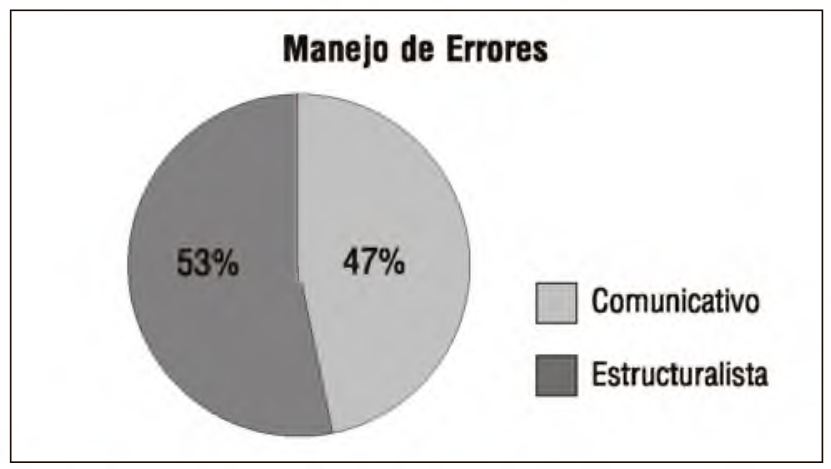

Fuente: Transcripciones de observaciones de clase

Observando las figuras 19,20 y 21 , podemos evidenciar que hay una gran divergencia sobre la forma como se corrigen los errores entre la opinión de los docentes, la percepción de los estudiantes y los resultados que se obtuvieron a través de las observaciones de clase. Para los profesores su forma de corregir los errores se encuentra categorizada dentro del enfoque comunicativo. Corrigen los errores indirectamente de tal manera que el estudiante no se sienta cohibido, y solo se corrigen aquellos que no interfieren con la comunicación. También se mencionaron otras como "peer correction". Sin embargo, los estudiantes y las observaciones muestran que los errores se corrigen en el momento que se cometen, pueden ser gramaticales o de pronunciación u otro tipo, y generalmente se recurre a la repetición para corregirlos. No se cumple con la espectativa de los enfoques comunicativos como lo plantea Larsen \& Freeman (2000), que se debe ser mas tolerante con los errores en el sentido de no corregirlos inmediatamente y de centrarse en aquellos que realmente dificulten la comunicación.

\subsubsection{Materiales y Recursos de instrucción}

En cuanto a los recursos que se utilizan con mayor frecuencia en las clases de inglés, los docentes mencionaron, en primer lugar el texto guía, seguido por grabadora, objetos reales y láminas. En esto coinciden los estudiantes y también se determinó lo mismo a través de las observaciones. Sin embargo, cabe señalar que en la mayoría de los casos el material se utiliza más con tendencia estructuralista que comunicativa, los docentes se enfocan en los ejercicios de corte precomunicativo que los textos fomentan, y no hay, en la mayoría de los casos, intencionalidad de adaptar o proponer tareas diferentes a las propuestas en este material.

\subsubsection{Técnicas de Instrucción}

La última categoría de análisis de las prácticas pedagógicas de los docentes de inglés corresponde a la utilización de técnicas de instrucción de carácter estructural y/o de carácter comunicativo, con base en las actividades que presenta Littlewood (1998).

Tabla 1. Prevalencia de técnicas de instrucción desde la perspectiva de estudiantes y profesores

\begin{tabular}{|l|l|l|l|l|l|l|}
\hline \multirow{2}{*}{$\begin{array}{l}\text { Perspectiva } \\
\text { Frecuencia }\end{array}$} & \multicolumn{3}{|c|}{ Estudiantes } & \multicolumn{3}{c|}{ Docentes } \\
\cline { 2 - 7 } & $\mathrm{AF}$ & $\mathrm{MF}$ & $\mathrm{BF}$ & $\mathrm{AF}$ & $\mathrm{MF}$ & $\mathrm{BF}$ \\
\hline Estructurales & $38 \%$ & $28 \%$ & $15 \%$ & $58 \%$ & $12 \%$ & $7 \%$ \\
\hline $\begin{array}{l}\text { Cuasi- } \\
\text { comunicativas }\end{array}$ & $25 \%$ & $29 \%$ & $23 \%$ & $15 \%$ & $39 \%$ & $24 \%$ \\
\hline Funcionales & $23 \%$ & $24 \%$ & $26 \%$ & $22 \%$ & $32 \%$ & $21 \%$ \\
\hline Sociales & $14 \%$ & $19 \%$ & $36 \%$ & $5 \%$ & $17 \%$ & $48 \%$ \\
\hline
\end{tabular}

Fuente: Encuestas a docentes y a estudiantes

Al respecto, tal como se puede apreciar en la Tabla 1, la mayoría de los estudiantes y de los docentes perciben que las actividades o técnicas de instrucción pre-comunicativas (estructurales y cuasi-comunicativas) han tenido una mayor frecuencia que las actividades comunicativas (funcionales y sociales).

Tabla 2. Ocurrencia de las técnicas de instrucción desde percepción de observadores

\begin{tabular}{|l|l|l|}
\hline Técnicas de instrucción & Ocurrencia & No ocurrencia \\
\hline Estructurales & $62 \%$ & $38 \%$ \\
\hline Cuasi-comunicativas & $83 \%$ & $17 \%$ \\
\hline Funcionales & $62 \%$ & $38 \%$ \\
\hline Sociales & $8 \%$ & $92 \%$ \\
\hline
\end{tabular}

Fuente : Transcripciones de observaciones de clase 
La Tabla 2 muestra la manera como los observadores valoran la ocurrencia de las cuatro tipos de técnicas de instrucción focalizadas en este estudio. Los observadores coinciden con los estudiantes y los docentes en cuanto a la prevalencia de las actividades pre-comunicativas. Sin embargo, los observadores reconocen una mayor frecuencia de las actividades funcionales.

3.2 Roles que desempeñan los aprendices y los docentes en el proceso enseñanza-aprendizaje del inglés

Este interrogante se resuelve igualmente con el aporte de las percepciones que ofrecen los estudiantes, los docentes y los observadores externos.

\subsubsection{Rol del profesor según la percepción de los docentes yestudiantes}

Figura 22. Percepción de docentes sobre sus roles

\section{Roles de los docentes desde su propia percepción}

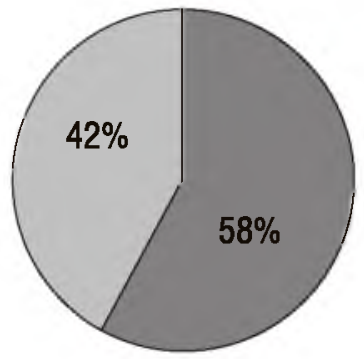

Estructuralista

Comunicativo

Fuente: Encuesta a docentes

Para determinar el rol que desempeñan los docentes de inglés del Departamento del Huila, una muestra representativa tanto de estudiantes, como de profesores fue escogida para responder a la encuesta aplicada. Los resultados fueron los siguientes:

Desde su propia percepción, como se puede apreciar en la figura 22, el $58 \%$ de los docentes consideran que los roles que desempeñan en las clases de inglés se enmarcan dentro de un enfoque comunicativo. El papel que sobresale es el de consejero, el cual consiste en proporcionar retroalimentación a los estudiantes a partir de las debilidades que muestren en el desarrollo de la competencia comunicativa, según lo establecido por Larsen \& Freeman (2010). En segundo lugar, los profesores manifiestan cumplir con el rol de administradores, el cual garantiza que la clase sea organizada de tal manera que el estudiante se involucre en el desarrollo de prácticas comunicativas.

Finalmente asumen un papel de co-comunicadores, que implica promover la interacción entre los estudiantes, siendo participante directo de las tareas, pero sin demostrar total control, solo estimulándolos a que participen activamente, (Harmer, 2007).
En cuanto al $42 \%$ de los profesores, ellos asumen también roles que están determinados dentro de un enfoque más estructuralista. Uno de esos roles es el de modelo que consiste en promover la repetición de palabras o frases con el objetivo de promover la práctica de pronunciación, o estructuras gramaticales, (Nunan, 2006).También afirman que realizan el papel de Informantes, lo cual significa demostrar gran habilidad para dar información acerca de la estructura de la lengua, (Harmer, 2007, p.108).

Figura 23. Roles del docente desde la percepción de los estudiantes

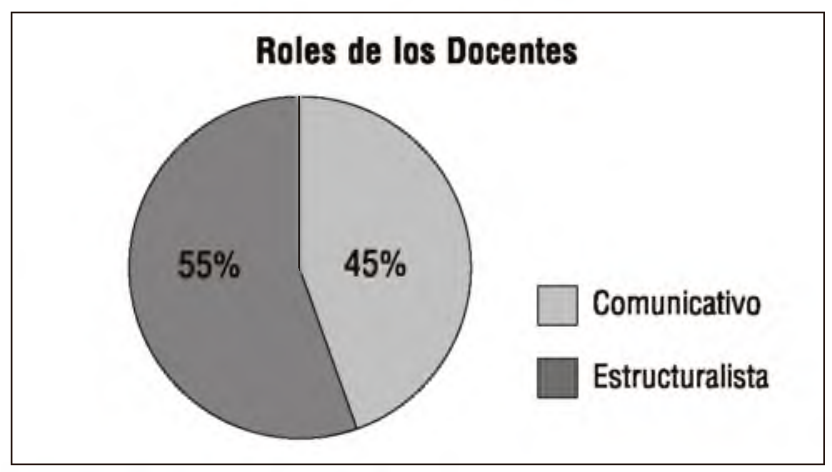

Fuente: Encuesta a estudiantes

De acuerdo a los resultados de la encuesta aplicada a los estudiantes, tal como lo muestra la figura 23, la mayoría de ellos, que corresponde al 55\%, opinan que los docentes desempeñan un rol más orientado a un desempeño tradicional. Entre estos encontramos el rol de modelo, que es quien controla y orienta el ritmo de la clase, y se enfoca más a la enseñanza de patrones gramaticales, (Larsen \& Freeman, 2010). En menor proporción se encuentra el rol de informante en donde el profesor muestra una gran habilidad para explicar estructuras de la lengua. (Harmer, 2007).

Por el contrario, el $45 \%$ reconocen que también los docentes asumen algunos roles que contribuyen al desarrollo de la competencia comunicativa. El primero es el de administrador, quien se asegura que en sus clases se fomenten prácticas comunicativas entre sus estudiantes. En segundo lugar aparece el rol de consejero orientado a ofrecer retroalimentación a partir de las debilidades que muestran sus estudiantes en el desarrollo de la competencia comunicativa, Diane Larsen \& Freeman (2010). Y un número muy pequeño de ellos considera que sus profesores participan activamente en las tareas sin asumir un rol tan protagónico, sino como promotores del uso de la lengua, es decir que son co-comunicadores. 
Figura 24. Roles del profesor desde la observación de clases

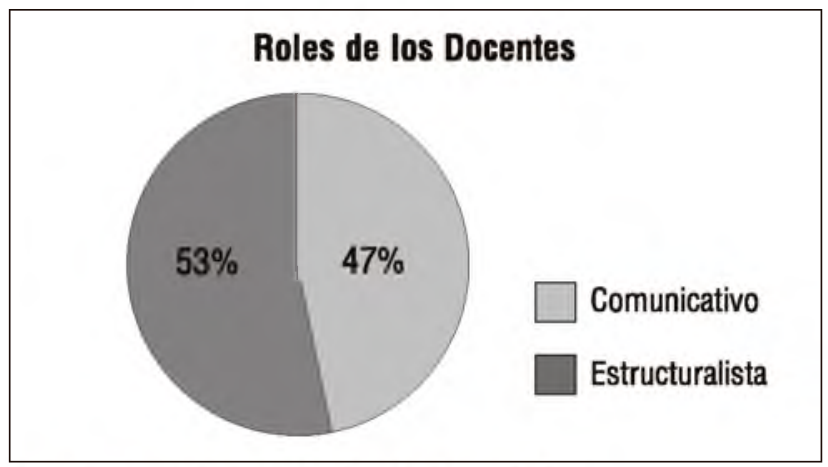

Fuente: Transcripciones de observaciones de clase

Estos resultados fueron comparados con la información recolectada a través de observaciones de clases que se realizaron a una muestra de profesores. De acuerdo con la figura 24 , el $47 \%$ de los docentes desempeñan roles comunicativos y el $53 \%$ roles estructuralistas. Esto nos indica que la percepción que tienen los docentes sobre su propio desempeño, el cual según ellos, refleja más una orientación comunicativa, no coincide con lo que se percibió a través de las observaciones ni con lo expresaron los estudiantes al respecto. Se evidencia que las prácticas pedagógicas en buena parte de la población educativa en el sector público del departamento del Huila, no cumplen plenamente con los parámetros legales, y los lineamientos teóricos sobre la orientación comunicativa del proceso de enseñanza-aprendizaje de una lengua extranjera.

\subsubsection{Roles de los aprendices en el proceso enseñanza-aprendizaje del inglés}

Figura 25. Apreciación de los roles del estudiante por parte de los profesores

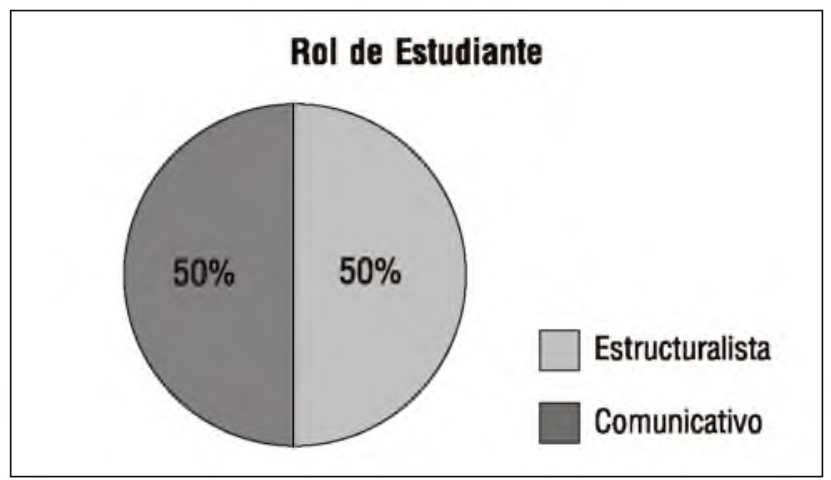

Fuente: Encuesta a docentes

Según la Figura 25, y desde las percepciones de los docentes, los estudiantes cumplen varios roles en las clases de inglés. El $65 \%$ consideran que sus alumnos desempeñan roles comunicativos tales como los de receptor activo y creativo, comunicador y aprendiz autónomo. El 33\% señalan que los estudiantes practican unos roles más estructuralistas tales como el de receptor pasivo y de imitador. El $2 \%$ no responde o alude a otros roles poco precisos que inicialmente no estaban contemplados en la encuesta, como afirmar que en "una clase con 40 estudiantes hay todo tipo de roles".

Figura 26. Auto-percepción de los roles del estudiante en las clases de inglés

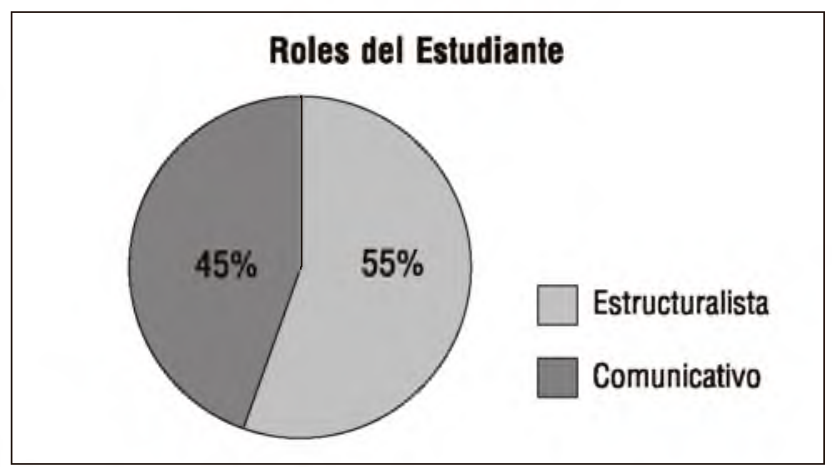

Fuente: Encuesta a estudiantes

Desde las percepciones de los propios estudiantes, ellos afirman que cumplen varios roles en las clases de inglés. La figura 26 muestra que el $45 \%$ de ellos admiten el cumplimiento de roles comunicativos tales como los de receptor activo-creativo y comunicador. El 55\% señala que practican unos roles más estructuralistas tales como el de receptor pasivo y de imitador.

Figura 27. Roles del alumno desde la observación de clases

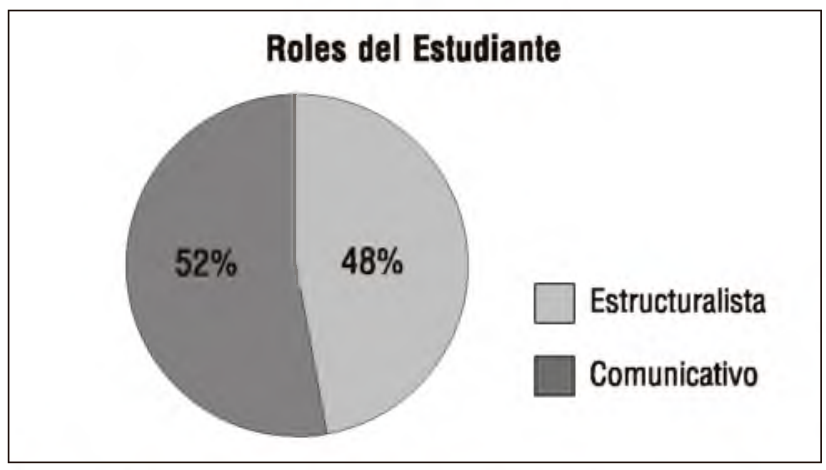

Fuente: Transcripciones de observaciones de clase

Desde el punto de vista de los observadores, el $64 \%$ de los alumnos cumplen roles comunicativos y el $36 \%$ roles estructuralistas. En este caso, se aprecia coincidencia con las valoraciones de los profesores sobre este asunto.

Con respecto al desempeño comunicativo del estudiante en las clases de inglés, Bastidas (1993) establece que el alumno debe jugar un papel activo y que debe ser responsable de su propio aprendizaje. 
Bastidas (1993) sostiene que "El estudiante debe ir independizándose poco a poco en su búsqueda de los nuevos conocimientos puesto que el ECO enfatiza en el aprender haciendo" (p.173). Por otro lado, Larsen \& Freeman (2010) añade que el aprendiz debe convertirse en un negociador de significados para entender a sus interlocutores y también hacerse entender, agrega que el estudiante debe ser ante todo communicador. Richards \& Rodgers (2004) por su parte señalan que el aprendiz debe ser un negociador entre el mismo, el proceso de aprendizaje y el objeto de estudio.

El alcance de los denominados roles estructuralistas que practican los estudiantes en sus clases de inglés puede comprenderse mejor desde algunos de los principios que promueve el audiolingualismo. Según Larsen \& Freeman (2010), el aprendizaje de una lengua en el Método Audiolingual es un proceso de formación de hábitos. Se asume que entre más a menudo se repite algo, más fuerte será el hábito y mayor será el aprendizaje (Pág. 43). En este orden de ideas, se ve a los estudiantes como imitadores de los modelos del docente; siguen las instrucciones de éste de la manera más precisa y rápida posible (Larsen \& Freeman, 2010, Pág. 45). Richards \& Rodgers (2004) afirman que los aprendices, desde una teoría conductista de aprendizaje, juegan un papel reactivo al responder a los estímulos del profesor y que tienen bajo control sobre el contenido, el ritmo o el estilo de aprendizaje (Pág. 62); es decir, que son unos receptores pasivos en el sentido de no tomar la iniciativa de interactuar con su profesor o sus compañeros para propósitos propiamente comunicativos.

3.3 Percepción de los factores que han favorecido y/o dificultado la implementación de los estándares básicos de competencia en lenguas extranjerasinglés en las instituciones educativas del Departamento del Huila

Figura 28. Implementación de estándares la desde perspectiva de los docentes

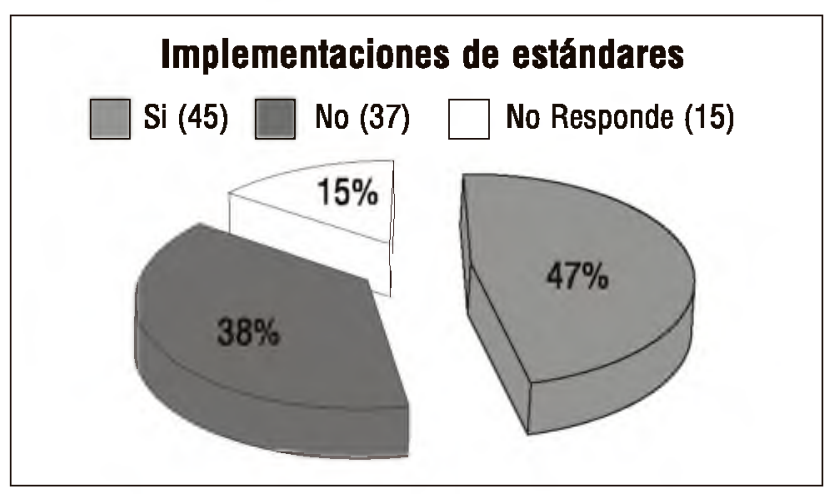

Fuente: Encuesta a docentes

Con respecto a los factores que, en opinión de los mismos docentes de inglés, han favorecido la implementación de los estándares, se logró establecer que en el 35\% de referencias se destaca la correlación entre estándares y programación curricular. En un $17 \%$, se hace referencia a la adaptación de los estándares a las necesidades de aprendizaje de los estudiantes al contexto. En otro $17 \%$, se resalta como factor el hecho de que la enseñanza del inglés se ha centrado en el desarrollo de competencias. En un 13\% de los comentarios, los docentes hacen alusión a la adopción del texto guía que adecuan contenidos y actividades a los estándares básicos. Finalmente, y con $4.5 \%$ de frecuencia cada uno, se mencionan los siguientes factores: claridad en los propósitos de aprendizaje, la intensidad horaria que se da en la media técnica, la formación profesional del docente y la lectura concienzuda de estándares.

Según la percepción de los docentes, los factores que han dificultado la implementación de los estándares de calidad son los siguientes: a) Escasa intensidad horaria y el bajo nivel de los estudiantes con 8 referencias cada uno de un total de 41 , correspondiente al 39\%. En segundo lugar, con 6 referencias cada uno, los profesores piensan que los estándares son muy ambiciosos para las condiciones de los colegios del sector público y del estudiantado. También consideran que hay falencias en las bases que traen los estudiantes de primaria en algunos casos porque los docentes que deben orientar las clases de inglés no son licenciados en el área. Y finalmente plantean que estos estándares no se ajustan al contexto real de las instituciones. Estos tres factores corresponden a un $43.9 \%$. Con un número menor de referencias se mencionan elementos como carencia de materiales, 3 referencias correspondiente al 7.3\%; grupos muy numerosos y desmotivación, y falta de interés por parte de los estudiantes, 2 referencias respectivamente, equivale al $9.8 \%$.

\section{Conclusiones}

El análisis de los resultados obtenidos a través del presente estudio nos permitió llegar a las siguientes conclusiones:

No obstante la existencia de las relativas mejores condiciones para la enseñanza del inglés tales como mayores niveles de formación de los docentes, progresos en las investigaciones, enfoques, teorías y modelos, avances en las políticas educativas, acceso por parte de docentes y estudiantes a nuevas tecnologías de la información y la comunicación, no se visualiza hoy por hoy un proceso instruccional del inglés centrado en prácticas pedagógicas suficientemente comunicativas que faciliten el desarrollo de las competencias que necesitan los alumnos para desenvolverse en un ambiente bilingüe.

A pesar de que se nota algunos avances en cuanto a la aplicación de los lineamientos teóricos sobre como desarrollar la competencia comunicativa en un idioma extranjero, los docentes se quedan cortos en la aplicación de los mismos; la mayor parte de las prácticas pedagógicas de los docentes son de carácter 
pre-comunicativo; es decir, prácticas estructurales o cuasi comunicativas; no se trasciende a la promoción de tareas de tipo funcional y social como las clasifica Littlewood, que son las que promueven al uso del idioma. Esto se ve reflejado en los resultados de las pruebas que se aplican a los estudiantes que ingresan a la universidad, solo el 25\% de ellos logran superar el nivel Al, la gran mayoría tiene que volver a empezar con la adquisición de las habilidades y los conocimientos básicos de esta lengua extranjera.

En cuanto al rol de los docentes y estudiantes en las clases de inglés, se notó cierta divergencia entre la percepción de los docentes, estudiantes y los observadores. Un alto número de docentes consideran que ellos están desempeñando roles que favorecen las prácticas comunicativas como consejeros, administradores y co-comunicadores; sin embargo, los estudiantes señalaron que el rol que ellos ven más reflejados en sus docentes es el de modelo, porque controla y orienta el ritmo de la clase, y se enfoca más a la explicación de la estructura de la lengua.

Con respecto al rol de los estudiantes, también se encontró cierto grado de divergencia entre las percepciones de los participantes del estudio. Los profesores consideran que sus estudiantes sí desempeñan un papel comunicativo, y en las clases observadas, también se notó esta tendencia en algunas instituciones, pero los estudiantes no están completamente de acuerdo; el 55\% de ellos señala que su rol es de receptor pasivo e imitador.

Consideramos que estas divergencias de percepción de estudiantes y docentes en cuanto a la caracterización de las prácticas pedagógicas en las clases de inglés, y la información recolectada a través de las observaciones, pueden originarse en primer lugar debido a la dificultad que tuvimos para observar suficiente número de clases que nos permitieran lograr corroborar con mayor solidez cual era la tendencia de los resultados. Por otra parte, los profesores fueron conocedores de los días que se realizarían las observaciones, lo cual puede incidir, hasta cierto punto, el desarrollo de sus clases.

Finalmente, se observa que aún hay dificultades en la apropiación e implementación de los estándares básicos de competencia en lenguas extranjeras. Los docentes argumentan que hay muchas circunstancias adversas que les impiden aplicarlos y alcanzar resultados positivos. Estas condiciones, tales como cursos numerosos, escasa intensidad horaria en la mayoría de colegios públicos, falta de materiales didácticos, entre otros, los lleva a concluir que los estándares son muy ambiciosos, y que no se ajustan a la realidad de nuestro contexto educativo.

\section{Recomendaciones}

Se precisa mayor capacitación de los docentes en cuestión de las políticas educativas pertinentes a la profesión, así como en los enfoques y tendencias recientes en la enseñanza comunicativa de los idiomas extranjeros.

Se necesita seguir analizando la situación de la enseñanza-aprendizaje del inglés, con un involucramiento más directivo y activo por parte de los mismos docentes.

Con base en estos diagnósticos, hay necesidad de construir propuestas de mejoramiento que sean implementadas en las diferentes instituciones educativas, en estrecha colaboración entre los docentes investigadores de la universidad y los profesores de inglés.

\section{Referencias Bibliográficas}

Bastidas, J. (1993). Opciones Metodológicas para la Enseñanza de Idiomas. JABA, Nariño.

Brown, D. (2007). Principles of language learning and teaching. Englewood Cliffs, NJ: Prentice Hall Regents.

Harmer, J. (2007).The Practice of English Language Teaching. Fourth edn Pearson \& Longman.

Hernández, S. R., Fernández, C., \& Baptista, L. P. (2006). Metodología de la Investigación. Mexico: MacGraw-Hill

Larsen-Freeman, D. (2010). Techniques and principles inlanguage teaching.Second edn.Oxford: Oxford University Press.

Littlewood, W. (1984).Foreign and Second Language Learning-Cambridge University Press.

Littlewood, W. (1998).Communicative Language Teaching.Cambridge University Press.

Ministerio de Educación Nacional. (2006). Estándares Básicos de Competencias en Lenguas Extranjeras: inglés. Imprenta Nacional

Nunan, D. (2006). Task-based language teaching. Cambridge University Press.

Richards, J. and Rodgers, T. (2004).Approaches and Methods in Language Teaching.Cambridge UniversityPress.

Universidad Surcolombiana. (2009). Acuerdo No. 065 del 18 de diciembre de 2009 del Consejo Superior, por el medio del cual se reglamenta el literal C artículo 33 de Acuerdo No. 049 de 2004. Recuperado de:

http://www.usco.edu.co/archivosUsuarios/12/publicaciones documentos/consejo_superior/consejo_superior_2009/acuerdo _065_de_2009.pdf

Ur, $\bar{P}$. (2009). A course in Language Teaching; Practice of Theory (Cambridge Teacher Training and Development). University Press.

Vanegas, L. E. \& Zambrano, L. C. (1995). Cómo Enseñar Inglés en Primaria: una Propuesta Metodológica. Hábeas litografía.

Zambrano, L. \& Insuasty, E. (2001). Aplicación del Enfoque Comunicativo a la Enseñanza-aprendizaje del Inglés en los Establecimientos de Secundaria en Neiva.Revista Entornos. No. 14. Universidad Surcolombiana. 